\title{
DEPRESSION AMONG INDIVIDUALS HAVING LOWER LIMB PHYSICAL DISABILITY
}

\author{
Muhammad Noor Faraz ${ }^{1,2 \otimes}$, Sayed Muhammad Sultan', \\ Shajaat Ali Khan', Shakirullah', Wajeeha Hameed'
}

\begin{abstract}
OBJECTIVE: To estimate the frequency of depression among individuals presenting with lower limbs physical disability (LLPD).
\end{abstract}

METHODS: This descriptive cross-sectional study was conducted from July 2016 to January 2017 at Khyber Teaching Hospital, Peshawar, Pakistan. A sample of 217 patients was enrolled through non-probability consecutive sampling technique. Participants of any age, both genders and having LLPD were included, while already diagnosed patients of depressive illness and/or patients using anti-depressant medications were excluded. Patient Health Questionnaire-9 (PHQ-9) scale was used in patients with LLPD. Statistical Analysis was done through SPSS-16.0.

RESULTS: Out of 217 participants, 156 (7I.88\%) were males. Mean age was $4 I \pm I 2.368$ years. Mean period of physical disability was $I 2 \pm 4.649$ years. Mean PHQ-9 scores was $12 \pm 3.313$. PHQ-9 score of $<4$ was observed in I 28 (58.99\%) patients while PHQ-9 score of $>4$ was present in 89 (4I.0I\%) patients. Hence, frequency of depression among patients with LLPD was $41.01 \%$. Male gender was predominant in both depressed $(n=64 / 89 ; 71.9 \%)$ and non-depressed $(92 / 128$; $71.9 \%)$ patients. About $45 \%$ of both depressed $(n=40 / 89)$ and non-depressed $(n=58 / 128)$ patients were aging $\leq 40$ years. About $61.8 \%(n=55 / 89)$ of depressed and $62.5 \%(n=80 / 128)$ of non-depressed patients were married. Majority of depressed patients $(n=44 / 89 ; 49.44 \%)$ and non-depressed patients $(n=62 / 128$; $48.44 \%$ ) were from lower socioeconomic status (SES). Extent of physical disability of $>10$ years was present in $59.55 \%(n=53 / 89)$ and $60.16 \%(n=77 / 128)$ depressed and non-depressed patients respectively.

CONCLUSION: In our study, about $41 \%$ of patients with LLPD were depressed and majority were male, married and belonging to lower SES.

KEY WORDS: Depression (MeSH); Lower limbs physical disability (Non-MeSH); Disabled Persons (MeSH); Psychiatric Rehabilitation (MeSH); Patient Health Questionnaire-9(MeSH)

THIS ARTICLE MAY BE CITED AS: Faraz MN, Sultan SM, Khan SA, Shakirullah, Hameed W. Depression among individuals having lower limb physical disability. Khyber Med Univ J 2020; I2(I):53-7. DOI: I0.35845/kmuj.2020.19735.

\section{INTRODUCTION}

$\mathrm{D}$ sability can be defined as an impairment that may be congenital, developmental, and mental or physical, which may significantly affects person life activities.'In 2014 World Health Organization (WHO), reported that more than ten million individual spend life with infirmity which estimated the fifteen percent of the world population. Individual between $2.2-3.8 \%$ had this disease for 15 years or more with significant complications in functioning. Moreover, the degrees of disability were increased in elderly peoples. ${ }^{2}$ In developing countries individuals with physical disabilities are mostly deprived of their basic health services. ${ }^{3}$ People with disabilities are open to numerous secondary situations includes pain, tiredness, depression, and obesity and other unidentified causes. ${ }^{4}$ Studies have also shown that depression itself limits the physical activity and in this way effects the quality
I. Department of Psychiatry, Khyber Teaching Hospital, Peshawar, Pakistan.

2. Department of Psychiatry, Khyber Medical University Institute of Medical Sciences (KMU-IMS), Kohat, Pakistan.

Email『:noorfaraz2002@gmail.com Contact \# : +92-345-9142463

$\begin{array}{ll}\text { Date Submitted: } & \text { September 28, 2019 } \\ \text { Date Revised: } & \text { February 28, 2020 } \\ \text { Date Accepted: } & \text { February 29, 2020 }\end{array}$

of life. Literature suggests that approximately II.3\% of all adults are affected by depression during any year of their lives.

Evidence shows depression was found to be $13.4 \%$ among individuals with lower limb prostheses users presented within five years of limb amputation. These psychological issues were believed to be associated with distress and adjustment complications in amputated individuals. ${ }^{6}$ Additionally, another study also showed that the high prevalence of anxiety and depression i.e. $37 \%$ and $20 \%$ respectively in individuals having amputation of limbs using Hospital Anxiety and Depression scales (HADS) and highlighted the importance of socio demographic factors in amputees. ${ }^{7}$ It is believed that in non-elderly patients, depression is related with commencement of physical disability and a stronger relation with inception of social disability was recorded. ${ }^{8}$ Likewise another study also found significant relationship between disability and depression, and the same study showed female predominance for depression. 9,10

A cohort study conducted, examined the reciprocal effects between depressive symptoms and functional disability a total of 753 elderly, which revealed that effective treatment and age related adaptation are of great importance in prevention, other than that the healthcare staff must target depressive illness of the patient for complete rehabilitation." In addition, few more studies also supported this positive relationship between physical infirmity and depression to conclude that physical disability results in depression which may vary depending 
TABLE I: SOCIODEMOGRAPHIC CHARACTERISTICS OF PARTICIPANTS

\begin{tabular}{|c|c|c|c|c|}
\hline Variables & Categories & $\begin{array}{c}\text { Depressed } \\
(\mathrm{n}=89)\end{array}$ & $\begin{array}{c}\text { Not Depressed } \\
(n=\mid 28)\end{array}$ & $\begin{array}{c}\text { Total } \\
(n=2 \mid 7)\end{array}$ \\
\hline \multirow{2}{*}{ Gender } & Male & 64 (71.9\%) & $92(71.9 \%)$ & I56 (7I.88\%) \\
\hline & Female & $25(28.1 \%)$ & $36(28.1 \%)$ & $6 \mathrm{I}(27.12 \%)$ \\
\hline \multirow{4}{*}{ Age (years) } & $\leq 30$ & $16(17.98 \%)$ & $23(17.96 \%)$ & 39 (I7.97\%) \\
\hline & $>30-40$ & $24(26.97 \%)$ & 35 (27.34\%) & 59 (27.19\%) \\
\hline & $>40-50$ & $27(30.33 \%)$ & 38 (29.7\%) & 65 (29.95\%) \\
\hline & $>50$ & $22(24.72 \%)$ & $32(25 \%)$ & 54 (24.89\%) \\
\hline \multirow{2}{*}{ Marital Status } & Single & 34 (38.2\%) & $48(37.5 \%)$ & 82 (37.78\%) \\
\hline & Married & 55 (61.8\%) & $80(62.5 \%$ & I35 (62.22\%) \\
\hline \multirow{3}{*}{$\begin{array}{l}\text { Socio- } \\
\text { economic } \\
\text { Status }\end{array}$} & $\begin{array}{l}\text { Lower Class } \\
(<10,000 / \text { month })\end{array}$ & 44 (49.44\%) & 62 (48.44\%) & 106 (48.85\%) \\
\hline & $\begin{array}{l}\text { Middle class } \\
(10,000-49000 / \text { month })\end{array}$ & 34 (38.20\%) & 49 (38.28\%) & 83 (38.25\%) \\
\hline & $\begin{array}{l}\text { Upper Class } \\
\text { (>50,000/month) }\end{array}$ & II (I2.36\%) & $17(13.28 \%)$ & 28 (I2.90\%) \\
\hline \multirow{4}{*}{ Education } & Illiterate & $43(48.31 \%)$ & $63(49.22 \%)$ & 106 (48.85\%) \\
\hline & Secondary & $21(23.60 \%)$ & 29 (22.66\%) & 50 (23.04\%) \\
\hline & Graduate & $13(14.61 \%)$ & $20(15.63 \%)$ & $33(15.21 \%)$ \\
\hline & Post-graduate & $12(13.48 \%)$ & $16(12.50 \%)$ & 28 (I2.90\%) \\
\hline \multirow{5}{*}{ Occupation } & House wives & II (I2.36\%) & $15(11.72 \%)$ & 26 (II.98\%) \\
\hline & Students & $13(14.61 \%)$ & $20(15.63 \%)$ & $33(15.21 \%)$ \\
\hline & Laborers & $3 \mathrm{I}(34.83 \%)$ & $45(35.16 \%)$ & $76(35.02 \%)$ \\
\hline & Professionals & $18(20.22 \%)$ & $25(19.53 \%)$ & $43(19.82 \%)$ \\
\hline & Businessmen & $16(17.98 \%)$ & $23(17.97 \%)$ & 39 (I7.97\%) \\
\hline \multirow{2}{*}{$\begin{array}{l}\text { Extent of Physical } \\
\text { Disability (years) }\end{array}$} & $\leq 10$ & $36(40.45 \%)$ & $5 \mathrm{I}(39.84 \%)$ & 87 (40.09\%) \\
\hline & $>10$ & $53(59.55 \%)$ & 77 (60.16\%) & 130 (59.9|\%) \\
\hline \multirow{2}{*}{$\begin{array}{l}\text { Patient Hospital } \\
\text { Questionnaire } \\
\text {-9 Score }\end{array}$} & $<4$ & $0(0 \%)$ & $128(100 \%)$ & I28 (58.99\%) \\
\hline & $\geq 4$ & 89 (100\%) & $0(0 \%)$ & 89 (4I.0I\%) \\
\hline
\end{tabular}

upon gender, age, disease course and disease duration. ${ }^{12,13}$

In a gender-stratified logistic reversion models, high depressive symptoms signified by the depression subscale of the Hopkins Symptom Checklist were allied with an amplified onset risk of Physical infirmity in actions of day-today life for both genders. ${ }^{14}$ In a study, depression following hip fracture showed significant association with increased physical disability and poor long term recovery after the injury, which concludes that this may be due to in creased cortisol to dehydroepiandrosterone sulphate (DHEAS) ratio causing depression and its correction may improve the long term outcome depending upon age, gender and social support. ${ }^{15-17}$ In Pakistan, studies have shown that high prevalence of anxiety and depression especially in those with physical disability. So, we planned this study to estimate the frequency of depression among individuals presenting with lower limbs physical disability. We focused on lower limb disability in particular as a scarce literature and data is available from our province of Khyber Pakhtunkhwa that has different cultural norms and is the most affected province by war and terrorism.

\section{METHODS}

This descriptive cross-sectional study design was conducted at Out Patient Department having lower limb physical disability of Orthopedics, Medicine and Physiotherapy in Khyber Teaching Hospital, Peshawar, Pakistan from $27 / 7 / 2016$ to $27 / 1 / 2017$. A sample size of 217 (males: I56 and females: 6I) was calculated via $\mathrm{WHO}$ calculator with confidence Interval of $95 \%$ and $5 \%$ of error. Samples were enrolled through non-probability consecutive sampling. Participants of any age, both genders and having lower limb physical disability were included, while all those participants already diagnosed of having any depressive illness by psychiatrists or physicians and/or were taking antidepressant medications or any other psychotropic disease were excluded from the study. Patient Health Questionnaire (PHQ-9) was used as research tool in this study and was used to diagnose depression. $\mathrm{PHQ}-9$ is a nine item scale with total score of 27 , a score of $>4$, for more than 2 weeks or more, was diagnostic of depression. This questionnaire was developed by Kroenke K, et al. ${ }^{23}$

After institutional ethical approval, informed written consent, and confidentiality assurance, data was collected via questionnaire. A predesigned performa incorporating personal information, demographics and questionnaire was used to collect the data. Statistical analysis was conducted using SPSS v.16.0. Descriptive statistics were applied on categorical and numerical variables and data was stratified for gender, marital status and $\mathrm{PHQ}$ scores.

\section{RESULTS}

Out of 217 participants, I56 (7I.88\%) 
were males and $6 \mathrm{I}(27.12 \%)$ were females. Mean age was $4 I \pm 12.368$ years. Mean period of physical disability was $12 \pm 4.649$ years. Mean PHQ-9 scores was $12 \pm 3.313$. PHQ-9 score of $<4$ was observed in 128 (58.99\%) patients while $\mathrm{PHQ}-9$ score of $>4$ was present in $89(4 \mathrm{I} .01 \%)$ patients. Hence, frequency of depression among patients with lower limbs physical disability was $41.01 \%$.

Male gender was predominant in both depressed $(n=64 / 89 ; 71.9 \%)$ and nondepressed (92/128; 71.9\%) patients (Table I). About $45 \%$ of both depressed $(n=40 / 89)$ and non-depressed $(n=58 / / 28)$ patients were aging $\leq 40$ years. About $61.8 \%(n=55 / 89)$ of depressed and $62.5 \%(n=80 / 128)$ of non-depressed patients were married. Majority of depressed patients ( $n=44 / 89 ; 49.44 \%)$ and non-depressed patients $(n=62 / 128 ; 48.44 \%)$ of were from lower socioeconomic status (SES). Extent of physical disability of $>10$ years was present in $59.55 \%(n=53 / 89)$ and $60.16 \%(n=77 / 128)$ depressed and non-depressed patients respectively.

\section{DISCUSSION}

This study determined that the occurrence of depression among individuals presenting with lower limb physical disability and the results indicated that depression was found to be $41 \%$ among patients presenting with lower limbs physical disability. This study indicates that mean age was $4 I \pm I 2.368$ with maximum of males and married as per marital status. This study had a high proportion of depression among its participants for which occupation, education and PHQ-9 scores were thoroughly analyzed.

As disability can be congenital or may be acquired at any time during the life. So, it has been mentioned by the WHO in 2014 that among more than one billion population around 15\% of the world's people are suffering from several sort of disabilities and among those one hundred ten million (2.2\%) to one hundred ninety million (3.8\%) people had this disease for 15 years or more and have got significant impairment in functionality. Moreover, the amount of disability is growing in this part of age due to senile changes and an escalation in enduring health circumstances. ${ }^{2}$

A study conducted supports findings of our current study and had reported that the proportions of people depression increased with physical disability such that $17.1 \%$ of people with physical disability experienced significant level of depression. ${ }^{12}$ Similarly in another study findings on individuals with lower limb amputation reported high rates of anxiety and depressive symptoms after amputation with prevalence up to $41 \%{ }^{24}$

A case control study was conducted on individuals having chronic neck pain and control, with each group having 40 male and 40 females. The study revealed that anxiety and depression was not only related with chronic neck pain but also the whole body fitness plays a significant role for which strategies should be followed accordingly to improve quality of life and outcome. ${ }^{25}$ Women may differ in their experience of pain, anxiety and depression when compared to men. Although gender did not significantly predict disability, however it does have some effects on the relationship between depression and disability, and in that when depression was high, women report greater disability than men do. Together these results not only suggest that gender is an important moderator of the relationship between emotional responses and disability, but also that such associations may be related more to depression than anxiety. ${ }^{25}$ Another longitudinal study also finding of this study that disability is a risk factor for depression, however female gender is not found to be a risk factor. The finding of the study also depicts that the effect of gender in the non-disability mostly in elderly group is limited. The gender differences in the disability group and the influence of culture on these differences need further research to be conducted. ${ }^{26,27}$

Among the married couples marital clash or other interpersonal relationship issues lead to upsurges in depression and functional impairment, thus affects the quality of life. Results propose marital conflict is a noteworthy risk issue for mental and physical health among middle aged and older adults. ${ }^{28}$
Our study results indicated that married patients were more depressed than single with lower limb physical disability supporting the findings of the previous studies.

A logistic regression model was used on the gender basis and revealed that the females are more depressed than male but in contrast to result of this study, which indicated that males are more depressed than female and this can be explained by male predominance in our society. ${ }^{29}$ Similarly, divorced patients were significantly more depressed than married or single. Patients with high disability scores were more depressed than non-disabled patients. In a study, binary logistic regression analysis revealed that higher depression scores were significantly associated with more than 3 children under guardianship $(p<$ $0.01)$ and higher disability scores $(p<$ $0.023),{ }^{30}$ thus physical disability significantly relates to depression affecting various aspects of life.

Survey based study design, weak sampling and a small sample size is among few limitations of this study. However, the results of this study can be used to initiate a study with better design and on a larger scale for better interpretation of this research's objective.

\section{CONCLUSION}

The current study concludes that suffering from lower limb physical disability were depressed particularly male, married, illiterate and labors of lower socio-economic class. Various strategies can be implemented to provide psychological support in the form of counseling and psychotherapies for complete recovery and rehabilitation. Furthermore, those rehabilitation centers working for individuals with physical disabilities must seek help from psychiatrists and clinical psychologists for complete management.

\section{REFERENCES}

I. World Health Organization (WHO). World report on disability $20 \mathrm{II}$. [Accessed on: October 28, 2016]. Available from: https://www. 
who.int/disabilities/world_report/2 0I I/report.pdf.

2. World Health Organization (WHO). Disability and health 2018. [Accessed on: October 26, 2016]. Available from: https://www.who. int/news-room/fact-sheets/detail/ disability-and-health.

3. Pharr J, Chino M. Predicting barriers to primary care for patients with disabilities: A mixed methods study of practice administrators. Disabil Health J 20 I 3;6(2): I I6-23. DOI: I0. I016/j.dhjo.2012.11.003.

4. Rimmer JH, Chen MD, Hsieh K. A conceptual model for identifying, preventing, and managing secondary conditions in people with disabilities. Phys Ther 20I I;9I(I2): I728-39. DOI: 10.2522/ptj.20I00 410.

5. Judd LL. Mood disorders in the general population represent an important and worldwide public health problem. Int Clin Psychopharmacol 1995; I0(Suppl 4):5-10. DOI: 10.1097/000048501995|2004-00002.

6. Atherton R, Robertson $\mathrm{N}$. Psychological adjustment to lower limb amputation amongst prosthesis users. Disabil Rehabil 2006;28(I9): | 20 |-9. DOI: I0.1080/ 09638280600551674.

7. Hawamdeh ZM, Othman YS, Ibrahim Al. Assessment of anxiety and depression after lower limb amputation in Jordanian patients. Neuropsychiatr Dis Treat 2008; 4(3):627-33. DOI: $10.2147 / \mathrm{ndt}$. s254I.

8. Ormel J, Vonkorff M, Oldehinkel AJ, Simon G, Tiemens BG, Üstün TB. Onset of disability in depressed and non-depressed primary care patients. Psychol Med 1999;29(4): 847-53. DOI: $10.1017 / \mathrm{s} 003329$ 1799008600.

9. Noh JW, Kwon YD, Park J, Oh IH, Kim J. Relationship between physical disability and depression by gender: a panel regression model. PLoS One 2016; I I(II): e0I66238.
DOI: $10.1371 /$ journal.pone.0166 238.

10. Bruce ML. Depression and disability in late life: directions for future research. Am J Geriatr Psychiatry 2001;9(2):102-12. DOI: 10.1097/ 000I9442-200105000-00003.

I I. Ormel J, Rijsdijk FV, Sullivan M, van Sonderen E, Kempen GI. Temporal and reciprocal relationship between IADL/ADL disability and depressive symptoms in late life. J Gerontol B Psychol Sci Soc Sci 2002 Jul I;57(4): 338-47. DOI: 10.1093/geronb/57. 4.p338.

12. Jones $\mathrm{KH}$, Jones PA, Middleton RM, Ford DV, Tuite-Dalton K, LockhartJones $\mathrm{H}$, et al. Physical disability, anxiety and depression in people with MS: an internet-based survey via the UK MS Register. PLoS One 20 I4;9(8): el 04604. DOI: I0.I37I/ journal. pone.0104604.

13. Gayman MD, Turner RJ, Cui M. Physical limitations and depressive symptoms: exploring the nature of the association. J Gerontol B Psychol Sci Soc Sci 2008; 63(4):S219-28. DOI: 10.1093/ geronb/63.4.s219.

14. Bruce ML, Seeman TE, Merrill SS, Blazer DG. The impact of depressive symptomatology on physical disability: MacArthur Studies of Successful Aging. Am J Public Health 1994 Nov;84(I I): 1796-9. DOI: 10.2105/ajph.84.II. 1796.

15. Phillips AC, Upton J, Duggal NA, Carroll D, Lord JM. Depression following hip fracture is associated with increased physical frailty in older adults: the role of the cortisol: dehydroepiandrosteronesulphate ratio. BMC Geriatr 2013;13:60. DOI: I0.II86/I47|-23|8-13-60.

16. Farooqi YN, Chaudhry M. Depression and anxiety reported by patients with cancer of the breast and uterus. Int J Humanit Soc Sci 2012;2(8): 188-93.

17. Al-Mohaimeed AA. Prevalence and factors associated with anxiety and depression among type 2 diabetes in Qassim: A descriptive crosssectional study. J Taibah Univ Med Sci 2017 Oct I;12(5):430-6. DOI: 10.1016/j.jtumed.2017.04.002.

18. Azeem MW, Dogar IA, Shah S, Cheema MA, Asmat A, Akbar M, et al. Anxiety and depression among parents of children with intellectual disability in Pakistan. J Can Acad Child Adolesc Psychiatry 2013;22 (4):290-5.

19. Bukhari FK, Mahamood YB, Saad ZB. Impact of Loneliness and Locus of Control on Depression of Elderly. J Bus Soc Rev Emerg Econ 20I5; I ( I):37-46.

20. Munawar M. Effects of Depression and Anxiety on Quality of Life of Physically Disabled Individuals [dissertation]. 2015. Department of Applied Psychology, The Islamia University of Bahawalpur. [Accessed on: April 10, 2019]. Available from URL: http://I2I.52. I 59. I54:8080/jspui/bitstream/I 234 56789/106 I/I/Effects\%20of\%20D epression\%20and\%20Anxiety\%2 0on\%20Quality\%20of\%20Life\%2 0of\%20Physically\%20Disabled\%2 Olndividuals.pdf.

21. Mohsin MN, Saeed W, Zaidi IH. Comorbidity of Physical Disability with Depression and Anxiety. Int J Environ Ecol Family Urban Stud 2013;3(I):79-88.

22. Pedras S, Carvalho R, Pereira MG. A predictive model of anxiety and depression symptoms after a lower limb amputation. Disabil Health J 20I8; I I(I):79-85. DOI: 10.1016/j. dhjo.2017.03.013.

23. Kroenke K, Spitzer RL, Williams JB The PHQ-9: validity of a brief depression severity measure. J Gen Intern Med 200I;I6(9):606-13. DOI: I0.I046/j.I525-I497.200I. 016009606.x.

24. Yalcinkaya H, Ucok K, Ulasli AM, Coban NF, Aydin S, Kaya I, et al. Do male and female patients with chronic neck pain really have different health-related physical 
fitness, depression, anxiety and quality of life parameters? Int J Rheum Dis 2017;20(9):1079-87. DOI: I0.1 I I I/I756-I85X.12389.

25. Keogh E, McCracken LM, Eccleston C. Gender moderates the association between depression and disability in chronic pain patients. Eur J Pain 2006; I (5):4 I 3-22. DOI: 10.1016/j.ejpain.2005.05.007.

26. Nolen-Hoeksema S. Gender differences in depression. Curr Dir Psychol Sci 200I Oct;10(5):I73-6. DOI: I0.1 I I I/|467-872I.00I42.
27. Vilaseca R, Ferrer F, Olmos JG. Gender differences in positive perceptions, anxiety, and depression among mothers and fathers of children with intellectual disabilities: a logistic regression analysis. Qual Quant 2014;48 (4):224 I-53. DOI: |0. I007/s | | |35013-9889-2.

28. Sezer S, Uyar ME, Bal Z, Tutal E, Ozdemir FA. The influence of socioeconomic factors on depression in maintenance hemodialysis patients and their caregivers. Clin Nephrol
20I3;80(5):342-8. DOI: 10.54|4/ CNI07742.

29. Hawamdeh ZM, Othman YS, Ibrahim Al. Assessment of anxiety and depression after lower limb amputation in Jordanian patients. Neuropsychiatr Dis Treat 2008 Jun;4(3):627. DOI: 10.2147/ ndt.s254l.

30. Choi H, Marks NF. Marital conflict, depressive symptoms, and functional impairment. J Marriage Fam 2008;70(2):377-90. DOI: I0. IIII/j. I74I-3737.2008.00488. $\mathrm{x}$.

\section{AUTHORS' CONTRIBUTIONS}

Following authors have made substantial contributions to the manuscript as under:

MNF: Acquisition of data, drafting the manuscript, final approval of the version to be published.

SMS: Analysis and interpretation of data, critical revision, final approval of the version to be published.

SAK \& Sh: Conception and study design, critical revision, final approval of the version to be published.

WH: Acquisition of data, drafting the manuscript, final approval of the version to be published

Authors agree to be accountable for all aspects of the work in ensuring that questions related to the accuracy or integrity of any part of the work are appropriately investigated and resolved.

\begin{tabular}{|c|}
\hline CONFLICT OF INTEREST \\
Authors declared no conflict of interest \\
GRANT SUPPORT AND FINANCIAL DISCLOSURE \\
NIL \\
\hline
\end{tabular}

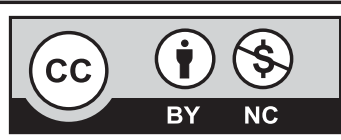

This is an Open Access article distributed under the terms of the Creative Commons Attribution-Non Commercial 2.0 Generic License.

KMUJ web address: www.kmuj.kmu.edu.pk

Email address: kmuj@kmu.edu.pk 